\title{
Roberto Di Stefano y José Zanca (Compiladores). Fronteras dispu- tadas: religión, secularización y anticlericalismo en la Argentina (siglos XIX y XX). Buenos Aires: Imago Mundi, 2016, 259 páginas.
}

\author{
María Victoria Núñez ${ }^{1}$
}

$E^{\prime}$ principal objetivo de este trabajo colectivo, compilado por Roberto Di Stefano y José Zanca, es presentar los cambios en las relaciones entre Estado, sociedad y religión en Argentina desde las primeras décadas del siglo XIX hasta los años '60 del XX. Los autores reunidos en esta obra trabajan temáticas que han sido desatendidas por la historiografía local, intentando iluminar el proceso de secularización argentino. El título de la obra es sugerente: la palabra "frontera" nos da la idea de límite, de aquello que ayuda a ubicar elementos de uno u otro lado. El libro reconstruye las disputas durante el proceso de laicización en nuestro país entre actores con una vocación clerical más marcada y actores decididamente detractores a ella. Esas fronteras buscaron marcar competencias, esferas de acción, presentando en ciertos momentos rigidez y en otros, distendimiento. La recopilación resulta un gran aporte debido a que, tal como señala Di Stefano en la introducción, se ha venido trabajando en profundidad en los últimos años sobre los procesos de secularización y laización en Argentina, no obstante, el anticlericalismo, sus prácticas y sus representaciones se han visto desatendidos. En esta dirección, es un trabajo que aporta y sugiere hebras para hilvanar futuras historias sobre el tema en el resto del país.

La pregunta con la que se abre Fronteras... es nodal "¿cómo se amalgamaron procesos globales como la conformación del Estado, la recepción de ideologías decimonónicas, el fenómeno inmigratorio y sus consecuencias políticas, los tópicos del discurso anticlerical y sus prácticas, la conformación de una esfera secular y la crisis de la modernidad, con sus apropiaciones y repercusiones locales?" Para responder este interrogante, los autores abordan sus objetos en diversos espacios de Argentina y procuran cubrir un amplio arco temporal. En este punto, la temporalidad resulta pertinente para un objeto que es vasto y variopinto, cuyas fronteras son difusas y dinámicas, en consecuencia, mutan al calor de los cambios políticos, sociales y culturales propios de

\footnotetext{
1 Instituto de Antropología de Córdoba-Universidad Nacional de Córdoba/Consejo Nacional de Investigaciones Científicas y Técnicas/Red de Estudios de Historia de la Secularización y la Laicidad. Argentina. Correo electrónico: mariavictoria.n@gmail.com
} 
la historia del país. En cuanto a los espacios y a las escalas de análisis, no es el mismo ejercicio de aproximación que ponen en juego los distintos autores, como el caso de Martín Castro que aborda los conflictos suscitados en San Isidro y Zárate, o el que realiza Ana María Rodríguez para La Pampa, o el de Ignacio Martínez y Diego Mauro, quienes analizan el territorio de la Argentina postrosista. Este abanico metodológico enriquece la mirada sobre el problema, mostrando sus aristas más sugerentes.

Algo que comparten los trabajos es que, además de describir las tendencias críticas al clero, se pregunta por las condiciones de posibilidad que tuvieron dichas expresiones. Esto es, tomar como excusa a las tendencias e ir un poco más allá, a los fines de iluminar los contextos más significativos de su ocurrencia. A la vez, se piensa al anticlericalismo como elemento fundamental a la hora de ubicar a la religión en el proceso de secularización, lo que lo convierte en una cuestión tan importante como la religión misma. Los trabajos se basan en un extenso y heterogéneo corpus documental que comprende prensa escrita, debates parlamentarios, fotografía, folletines y panfletos; estas fuentes posibilitaron restituir las diversas maneras en que circulaban sentidos y se propalaban ciertos significados.

El libro analiza, entonces, aspectos del proceso de secularización en diversos espacios de Argentina, país que vivenció ese proceso de modo diferente a lo acontecido en México, en Brasil o en Uruguay. Allí, Iglesia y Estado no llegaron nunca a una ruptura total, lo que hace importante estudiar el fenómeno y sus peculiaridades. La virulencia de los conflictos y las tensiones no parecieran ser iguales en intensidad en los distintos casos analizados y aún resta indagar acerca del fenómeno en otros espacios geográficos argentinos.

Al primer capítulo lo firman Ignacio Martínez y Diego Mauro, abarca el período comprendido entre 1820 y 1890. La idea que subyace al trabajo es que resulta mucho más potente abandonar el presupuesto de la separación de Iglesia y Estado como el final obvio del proceso de modernización político abierto con las revoluciones. Por el contrario, los autores ponen el acento en las diversas formas en que fueron mutando las relaciones entre Estado e Iglesia en la larga duración. Proponen una lectura sagaz del problema, advirtiendo al lector sobre la relativa indeterminación de competencias tanto de la Iglesia como del Estado en los años posrevolucionarios. A lo largo del relato, sacan a la luz nodos problemáticos que posibilitan dilucidar la complejidad del proceso: se disputan cuestiones tales como el nombramiento de los obispos, el lugar relativo de la religión en la naciente nación, el presupuesto estatal destinado al culto, la relación con la Sede Pontificia, entre otras. Estudiar estos aspectos del problema posibilita iluminar cuestiones que exceden por mucho a lo religioso, 
se trata de cuestiones culturales y políticas que en el fondo delimitaban y daban sentido al vínculo entre Estado e Iglesia.

El capítulo siguiente, de Roberto Di Stefano, recorta como objeto las tensiones habidas entre clericales y anticlericales durante el decenio que va desde 1852 a 1862. El autor divide al período en tres y señala que el punto máximo de conflictividad se desató luego de la expulsión del seno de la Iglesia a las sociedades masónicas, tras la pastoral de Escalada, en 1857. El autor advierte cómo la conflictividad del período va in crescendo. La década se abre con un momento de relativa connivencia de intereses entre los sectores eclesiásticos y los laicos, después de la caída de Rosas, quien había legado una Iglesia en situación calamitosa. Así las cosas, entre 1852 y 1855 el autor marca un período en el que el presupuesto dedicado al culto se vio engordado y las relaciones fueron armónicas. No obstante, durante esos años se comienza a gestar un cuestionamiento al "ultramontanismo" de algunos representantes del clero por parte de sectores críticos a la Iglesia. Es un trabajo por demás interesante, que pone en evidencia cómo los sectores clericales y los anticlericales se valieron de las herramientas provistas por la modernidad -la prensa escrita, el asociacionismo, la tribuna política- para hacer circular sus ideas en los diversos enfrentamientos. Fue la pastoral lo que hizo estallar el conflicto, arremetió contra las sociedades masónicas y las relaciones se tensaron al máximo. A lo largo del trabajo se pone en evidencia cómo la cuestión es mucho más compleja: por aquéllos años, la doble pertenencia -a la Iglesia y a la masonería- no era una cuestión atípica. Di Stefano señala cómo fue la lógica política, más que la ideológica, la que solía dictar las prioridades del gobierno.

El capítulo siguiente, a cargo de Martín Castro, justifica la elección de centrar el análisis en un solo año, 1911, para seguir las reacciones de sectores anticlericales en la provincia de Buenos Aires. Su interés radica en que ilustra cómo el panorama social en los años del Centenario se complejiza y se diversifica: efectivamente hubo cierto "agotamiento del impulso secularizador" y la ocupación de algunos Ministerios claves por figuras adeptas al catolicismo, arena propicia para que se dinamicen movilizaciones y acciones colectivas para revertirlo. El autor toma las protestas habidas en dos localidades, Zárate y San Isidro, como prismas para iluminar la activación de comités, logias y agrupaciones liberales y anticlericales en toda la provincia bonaerense. A través del análisis de los discursos anticlericales, de los temas en común, las preocupaciones, las denuncias, los mitines y los usos del espacio y del calendario, el autor restituye eventos que por mucho exceden su condición "local". Estos eventos se encadenan en una red de relaciones a nivel nacional que se activaban al estallar un foco de conflicto, sintomáticos del problema de los límites de 
las relaciones entre Estado e Iglesia.

En el siguiente trabajo, Ana María Rodríguez estudia los conflictos habidos entre socialistas, en tanto anticlericales, y católicos en la disputa en torno a un territorio de reciente colonización como fue La Pampa. Resulta muy atractivo el modo en que la autora reconstruye las tensiones que enfrentó el catolicismo en esta sociedad "nueva", que nació plural a diferencia de antiguas zonas de colonización. Pretende comprender cómo, en el proceso de conformación del campo religioso, los agentes eclesiales confrontaron con grupos anticlericales. En La Pampa engrosaron las filas anticlericales masones, liberales, maestros normalistas, protestantes, socialistas, espiritistas, integrantes de asociaciones de inmigrantes. Los principales enfrentamientos entre éstos y los sectores católicos se dieron en torno al rumbo de la educación, los problemas de la construcción de la nación, el control del espacio público, la cuestión cultural y la vida política del territorio. Principalmente, es en el terreno educativo donde se vieron las mayores tensiones: salesianos y laicos se disputaron la enseñanza de los niños pampeanos. Con el correr del tiempo, los conflictos se trasladan a los Ministerios, donde socialistas y liberales Ilegaron a tener más protagonismo y el clero se vio interpelado a dar batalla por la hegemonía de esos espacios.

El capítulo final está a cargo de José Zanca y analiza las diversas expresiones de lo religioso en relación a la crisis de la modernidad y el desarrollo de una contracultura local en la década de 1960, principalmente en Buenos Aires. Demuestra, a través de su trabajo, que el proceso de secularización no implica necesariamente la muerte de la religiosidad, bien por el contrario, se constata durante esos años una intensificación de la diversidad religiosa. Estudia casos de consumo religioso, sintomáticos de las demandas de la sociedad ante una crisis de paradigmas. En este contexto, la religión ya no es algo a combatir. Entendiendo el sentido de lo religioso y de lo secular como campos volubles, productos históricamente producidos y mudables, busca escribir una historia social de la secularización atenta a los modos en que una sociedad que ya no vive en una era religiosa, imagina, piensa y construye lo religioso. Así, esboza la hipótesis de que la sociedad argentina de los años '60 puso en crisis la estructura cognitiva propia de la modernidad, ante lo cual, ni Iglesia ni Estado pudieron dar respuestas superadoras. Así, las mutaciones habidas en la religión son un fenómeno conectado intrínsecamente a estos cambios. A lo largo de su capítulo conocemos formas alternativas de religiosidad que se adaptaron con más facilidad a los esquemas en los que se insertó el individuo posmoderno, vivenciando una religiosidad más plural. Ante la crisis, surge una miríada de interpretaciones de la realidad, lo que da cuenta de la inscripción de la historia religiosa del período en la historia sociocultural más general. 
En resumen, consideramos que este libro resulta un aporte importante para el campo de estudios de la religión en la medida que los autores despliegan diversos y sugerentes modos de abordar sus objetos, que hacen que esta obra sea una herramienta para quienes trabajen la temática. En cada capítulo encontramos una mirada crítica y plural, que pone en duda los lugares comunes y que procura restituir cuadros de situación de un fenómeno complejo, que se activa y se desactiva, que tiene mayor o menor virulencia conforme a los contextos en los que ocurre. Resulta, en consecuencia, un trabajo ineludible y el resultado de un esfuerzo colectivo por restituir las aristas de la difícil separación de las esferas estatales y eclesiásticas y del lugar que debe tener lo religioso. 